\title{
Erythropoietin Exacerbates Inflammation and Increases the Mortality of Histoplasma capsulatum-Infected Mice
}

\author{
Gisele Aparecida Locachevic, ${ }^{1}$ Priscilla Aparecida Tartari Pereira, \\ Adriana Secatto, ${ }^{1}$ Caroline Fontanari, ${ }^{1}$ Alyne Fávero Galvão, ${ }^{1}$ \\ Morgana Kelly Borges Prado, ${ }^{1}$ Karina Furlani Zoccal, ${ }^{1}$ Tânia Petta, \\ Luiz Alberto Beraldo Moraes, ${ }^{2}$ Simone Gusmão Ramos, ${ }^{3}$ Fabíola Attie de Castro, ${ }^{1}$ \\ Carlos Artério Sorgi, ${ }^{1}$ and Lúcia Helena Faccioli ${ }^{1}$ \\ ${ }^{1}$ Departamento de Análises Clínicas, Toxicológicas e Bromatológicas, Faculdade de Ciências Farmacêuticas de Ribeirão Preto, \\ Universidade de São Paulo, 14040-903 Ribeirão Preto, SP, Brazil \\ ${ }^{2}$ Departamento de Química, Faculdade de Filosofia, Ciências e Letras de Ribeirão Preto, Universidade de São Paulo, \\ 14040-901 Ribeirão Preto, SP, Brazil \\ ${ }^{3}$ Departamento de Patologia e Medicina Legal, Faculdade de Medicina de Ribeirão Preto, Universidade de São Paulo, \\ 14049-900 Ribeirão Preto, SP, Brazil
}

Correspondence should be addressed to Lúcia Helena Faccioli; faccioli@fcfrp.usp.br

Received 4 March 2015; Accepted 19 May 2015

Academic Editor: Magdalena Klink

Copyright (c) 2015 Gisele Aparecida Locachevic et al. This is an open access article distributed under the Creative Commons Attribution License, which permits unrestricted use, distribution, and reproduction in any medium, provided the original work is properly cited.

\begin{abstract}
Erythropoietin (EPO) is a key hormone involved in red blood cell formation, but its effects on nonerythroid cells, such as macrophages, have not been described. Macrophages are key cells in controlling histoplasmosis, a fungal infection caused by Histoplasma capsulatum $(\mathrm{Hc})$. Considering that little is known about EPO's role during fungal infections and its capacity to activate macrophages, in this study we investigated the impact of EPO pretreatment on the alveolar immune response during $H c$ infection. The consequence of EPO pretreatment on fungal infection was determined by evaluating animal survival, fungal burden, activation of bronchoalveolar macrophages, inflammatory mediator release, and lung inflammation. Pretreatment with EPO diminished mononuclear cell numbers, increased the recruitment of $\mathrm{F} 4 / 80^{+} / \mathrm{CD} 80^{+}$and $\mathrm{F} 4 / 80^{+} / \mathrm{CD} 6^{+}$cells to the bronchoalveolar space, induced higher production of IFN- $\gamma$, IL-6, MIP- $1 \alpha$, MCP-1, and $\mathrm{LTB}_{4}$, reduced $\mathrm{PGE}_{2}$ concentration, and did not affect fungal burden. As a consequence, we observed an increase in lung inflammation with extensive tissue damage that might account for augmented mouse mortality after infection. Our results demonstrate for the first time that EPO treatment has a deleterious impact on lung immune responses during fungal infection.
\end{abstract}

\section{Introduction}

Histoplasmosis caused by the dimorphic fungus Histoplasma capsulatum $(H c)$ is a granulomatous disease that primarily affects the lungs [1]; however, depending on the immune status of the host and the inhaled fungal load, the infection can progress to chronic pulmonary and disseminated diseases leading to death [2]. Alveolar macrophages are the main cell type involved in the phagocytosis and death of $H c$. These yeasts may multiply inside macrophages, inducing cell death. However, when an appropriate immune response is triggered, alveolar macrophages are activated, killing intracellular $\mathrm{Hc}$ and controlling the infection [3]. Host control and eradication of $H c$ infection are mediated by a $\mathrm{T}$ helper type 1- (Th1-) mediated cellular immune response, which is associated with production of IL-12, IFN- $\gamma$, and TNF- $\alpha$, and activation of macrophages, dendritic cells, and Thelper lymphocytes [1]. Besides cytokines, lipid mediators are essential for host defense against $H c$. Previously, we demonstrated that leukotrienes (LTs), lipid mediators derived from arachidonic 
acid metabolism [4], play an important role in primary and secondary immune responses during histoplasmosis by increasing phagocytosis and killing by macrophages [5-7]. By contrast, prostaglandins (PGs) enhance $H c$ infection [8]. Innate, sentinel dendritic cells, neutrophils, and mainly tissue macrophages are major producers of eicosanoids [9], as well as cytokines [10].

Considering the importance of macrophages for infection control, we can suggest that the enhancement of their effector activities might be critical and decisive to the fate of infections. We found a study by Lifshitz et al. [11] that shows that treatment with erythropoietin (EPO) activates the biological functions of macrophages. They observed that peritoneal macrophages and bone marrow-derived macrophages from EPO-treated mice have increased phagocytic rates and nitric oxide production but a reduction in IL-12 and IL-10. Indeed, macrophages are now considered a target for EPO.

$\mathrm{EPO}$ is a hormone that is classically known for regulating red blood cell production. In adults, EPO is produced and secreted primarily by kidney tubular cells $[12,13]$. The nonerythroid effects of EPO have been described [14, 15] such as their role in immune system activation for controlling some infections. Nishimura et al. [16] showed that the absence of EPO production decreases bone marrow erythropoiesis and aggravates anemia during Trypanosoma brucei brucei infection. In addition, EPO has been administered to patients with infectious diseases to treat pathogen-induced hemolytic anemia [17]. During Plasmodium berghei infection, administration of EPO prolonged mouse survival without affecting parasitemia. This phenomenon is likely due to the fact that EPO ameliorated parasite-induced anemia, reduced TNF$\alpha$ and IFN- $\gamma$ production, and decreased neuronal apoptosis, representing a potential therapeutic benefit in cerebral malaria [18]. In contrast to that reported for protozoal infections, EPO treatment in cases of Salmonella typhimurium infection increased the mortality of mice and decreased the production of IL-6, TNF- $\alpha$, and IL-1 $\beta$ in the liver [19]. To the best of our knowledge, there are no reports evaluating the effect of EPO pretreatment in fungal infections such as histoplasmosis.

Investigations of the relationship between EPO and LTs and PGs have been somewhat limited. Mason-Garcia et al. [20] demonstrated that erythrocytes in the presence of EPO increase the production of $\mathrm{LTB}_{4}$ and 12-hydroxyeicosatetraenoic acid, and they suggested that this increase may be related to the activation of phospholipase $\mathrm{A}_{2}$ and $\mathrm{C}$. However, nothing is known about the relationship between EPO and lipid mediator production in fungal infections. The role of EPO in PG synthesis or action has not been described, although some studies demonstrated the effects of PGs in EPO production or action [21-23]. Considering that macrophages and lipid mediators are important for the control of $\mathrm{Hc}$ infection and that EPO might act on these two parameters, our aim was to investigate the effects of EPO pretreatment on experimental histoplasmosis. We found that EPO pretreatment increased the mortality of infected mice, the number of cells expressing CD80 and CD86 in the F4/80 population, and the production of inflammatory cytokines, chemokines, and $\mathrm{LTB}_{4}$ and upregulated late apoptosis. On the other hand, no alteration of fungal burden (CFU) was observed, and the number of mononuclear cells recruited to bronchoalveolar lavage fluid (BALF) was reduced, as well as $\mathrm{PGE}_{2}$ production. When extrapolated to humans, our study suggests that the use of EPO for the treatment of anemia in patients with chronic renal disease might impair the control of fungal infections such as those caused by $H c$, leading to lung inflammation, tissue damage, and death.

\section{Materials and Methods}

2.1. Mice. Male, 8-week-old C57Bl/6 mice were obtained from the Faculdade de Ciências Farmacêuticas de Ribeirão Preto, Universidade de São Paulo (Ribeirão Preto, SP, Brazil). Uninfected mice, treated with EPO and untreated, were kept at the animal facility of Faculdade de Ciências Farmacêuticas de Ribeirão Preto with a $12 \mathrm{~h}$ light/dark cycle and with water and food ad libitum. After $H c$ infection, mice were kept in a biohazard facility in safety enclosures and under the same standard husbandry conditions used for uninfected mice. All procedures were performed following the guidelines of the Animal Care Committee of Universidade de São Paulo (protocol number 11.1.464.53.0).

2.2. EPO Treatment. Recombinant human EPO (rHuEPO; HEMAX, from Biosintética-Aché, Brazil) was diluted in phosphate-buffered saline (PBS) before use. The dose was chosen based on that used by Lifshitz et al. [11] and on a doseresponse $(45,50,100,150$, and $180 \mathrm{U}$ of EPO) trial performed in our laboratory as pilot experiments (data not shown). The dose of $45 \mathrm{U}$ of EPO in $100 \mu \mathrm{L}$ of PBS was selected and administered subcutaneously to each mouse three times per week for one week prior to $\mathrm{Hc}$ infection.

2.3. Histoplasma capsulatum Strain and Infection. The $\mathrm{Hc}$ isolate used in this study was obtained from a patient at the Hospital das Clínicas de Ribeirão Preto (Ribeirão Preto, SP, Brazil) and maintained in our lab. The mycelial phase of $\mathrm{Hc}$ was obtained as previously described [5]. To obtain yeasts, mycelia were cultivated at $37^{\circ} \mathrm{C}$ in $\mathrm{BHI}$ blood agar. Samples were used when fungal viability was $\geq 90 \%$, based on fluorescein diacetate and ethidium bromide exclusion assays, performed as previously described [24].

Mice were infected with $\mathrm{Hc}$ as previously described [5]. Briefly, animals were anesthetized, and their tracheae were exposed. Then $100 \mu \mathrm{L}$ of PBS without or with a sublethal $(5 \times$ $10^{5}$ yeasts/mouse) or lethal $\left(1 \times 10^{6}\right.$ yeasts/mouse $)$ inoculum of viable $H c$ cells was inoculated intratracheally (i.t.). Mice were euthanized 14 days after infection in a $\mathrm{CO}_{2}$ chamber for lung, spleen, and bronchoalveolar fluid analyses. Uninfected and untreated mice were euthanized on the same day as infected animals.

2.4. Experimental Design. In this study, we used the following 4 experimental groups of mice to evaluate the effect of EPO pretreatment in $H c$ infection: (1) untreated and uninfected mice (control), (2) uninfected (but inoculated i.t. with $100 \mu \mathrm{L}$ PBS) mice treated with EPO s.c. for one week (EPO group), 
(3) untreated (but inoculated s.c. with $100 \mu \mathrm{L}$ of PBS) mice infected i.t. with $\mathrm{Hc}$ (Hc group), and (4) mice pretreated s.c. with EPO for one week and then infected i.t. with $\mathrm{Hc}(E P O+$ Hc group).

2.5. Bronchoalveolar Lavage Fluid (BALF) Collection. BALF was harvested by carefully injecting $1 \mathrm{~mL}$ of PBS into the lungs. This procedure was repeated three times and the recovered fluid was pooled. Total cell counts in BALF samples were achieved using a Neubauer chamber, and differential cell counts were performed using cytospin preparations stained with Panoptic (Laborclin, Paraná, Brazil) [5].

2.6. Assessment of Fungal Burden in the Lungs and Spleen. The recovery of $H c$ from mouse lung and spleen was performed as previously described [25]. Two serial dilutions of tissue homogenates were made in PBS and $100 \mu \mathrm{L}$ of each diluted homogenate sample was placed on $\mathrm{BHI}$-agar-blood medium and then incubated for 15 days at $37^{\circ} \mathrm{C}$ and with $5 \% \mathrm{CO}_{2}$. Fungal colonies were counted manually and the fungal burden was expressed as the number of colony-forming units per gram of tissue (CFU/g).

2.7. Histology. Lungs collected from mice 14 days after infection were fixed in $10 \%$ formalin, processed, and embedded in paraffin blocks, from which $5 \mu \mathrm{m}$ sections were cut and stained with hematoxylin and eosin (H\&E). Stained tissue sections were analyzed with a Leica DMR light microscope (Leica Microsystems GmbH, Wetzlar, Germany) equipped with a video camera (Leica Microsystems Ltd., Heerbrugg, Switzerland). Images were analyzed using the Leica Application Suite software (Leica Microsystems Image Solutions, Cambridge, UK), and the lung-lesion area (LLA) was estimated by computerized planimetry analysis of the images using the CS3 Photoshop software (Adobe, San Jose, CA, USA) and expressed as a percentage of the total lung tissue area using the formula (LLA/TA) $\times 100$, where TA is the total lung tissue area.

2.8. Measurement of $P G E_{2}$ and $L_{T B}$ Concentrations. To obtain tissue homogenates, lungs were removed from mice immediately after euthanasia and homogenized using a Mixer Homogenizer (Labortechnik, Wasserburg am Bodensee, Germany) in $2 \mathrm{~mL}$ of RPMI-1640 containing $10 \mu \mathrm{M}$ indomethacin and $1 \mathrm{mM}$ EDTA. After centrifugation, supernatants were recovered, filtered, and acidified to $\mathrm{pH}$ 3.4-3.6 using $1 \mathrm{~N} \mathrm{HCl}$ and applied slowly to a Sep-Pak $\mathrm{C}_{18}$ column (Waters, Milford, MA, USA) previously washed with $20 \mathrm{~mL}$ of $35 \%$ ethanol and $20 \mathrm{~mL}$ of water. After washing the columns with water, the lipids were eluted with $2 \mathrm{~mL}$ of absolute ethanol, dried under vacuum, and reconstituted in $100 \mu \mathrm{L}$ of methanol. Samples were centrifuged to remove any indomethacin precipitate, and the supernatants were transferred to appropriate vials for determination of the concentration of $\mathrm{PGE}_{2}$ and $\mathrm{LTB}_{4}$ by high-performance liquid chromatography-tandem mass spectrometry using an Acquity UPLC-MS system coupled to a Xevo TQ-S mass spectrometer (Waters). Chromatographic separation was conducted using a Supelco Ascentis EXPRESS $\mathrm{C}_{18}$
HPLC column (Sigma-Aldrich, St. Louis, MO, EUA) with dimensions of $100 \mathrm{~mm} \times 3.0 \mathrm{~mm}, 2.7 \mu \mathrm{m}$. A binary gradient system was employed in which phases $\mathrm{A}$ and B consisted of water/acetonitrile/acetic acid $(70: 30: 0.02, \mathrm{v} / \mathrm{v})$ and acetonitrile/isopropanol $(70: 30, \mathrm{v} / \mathrm{v})$, respectively. Samples $(10 \mu \mathrm{L})$ were eluted with a flow rate of $0.6 \mathrm{~mL} / \mathrm{min}$, with a linear gradient starting with $0 \% \mathrm{~B}$, which was increased to $15 \% \mathrm{~B}$ at $2 \mathrm{~min}, 20 \% \mathrm{~B}$ at $5 \mathrm{~min}, 35 \% \mathrm{~B}$ at $8 \mathrm{~min}, 40 \% \mathrm{~B}$ at $11 \mathrm{~min}, 100 \% \mathrm{~B}$ at $15 \mathrm{~min}, 100 \% \mathrm{~B}$ at $18 \mathrm{~min}$, and $0 \% \mathrm{~B}$ at $19 \mathrm{~min}$ and held there for $30 \mathrm{~min}$. Analyses were performed using multiple reaction monitoring (MRM) scan mode employing negative ionization. MRM transitions were $351.2 \rightarrow 171$ for $\mathrm{PGE}_{2}$ and $335.1 \rightarrow 195$ for $\mathrm{LTB}_{4}$. Quantification was accomplished using calibration lines constructed with $\mathrm{PGE}_{2}$ and $\mathrm{LTB}_{4}$ synthetic standards (Cayman Chemical, Ann Arbor, MI, USA). Data were collected and analyzed using the software Mass Lynx 4.0 (Waters).

\subsection{Quantification of Cytokine and Chemokine Concentra-} tions. The concentrations of IFN- $\gamma$, IL-6, MCP-1, and MIP$1 \alpha$ in supernatants of lung homogenates were determined using commercially available ELISA kits according to the manufacturer's instructions ( $\& \& D$ Systems, Minneapolis, $\mathrm{MN}$, USA). Sensitivities were $>10 \mathrm{pg} / \mathrm{mL}$.

2.10. Analysis of Macrophage Activation by Flow Cytometry. Cells from mouse BALF samples were double-labeled for flow cytometric analysis as previously described [7], using combinations of the following fluorochrome-conjugated monoclonal antibodies: anti-F4/80-PerCP, anti-CD80-PE, antiCD86-APC, and anti-MHC II-FITC (all from BD Bioscience, San Jose, CA, USA). Samples were analyzed in a FACSCanto flow cytometer (BD Bioscience), and the percentage of cells double-positive for $\mathrm{F} 4 / 80^{+} \mathrm{CD} 80^{+}, \mathrm{F} 4 / 80^{+} / \mathrm{CD} 86^{+}$, and $\mathrm{F} 4 / 80^{+} / \mathrm{MHC} \mathrm{II}^{+}$were calculated using the FACSDiva software (BD Bioscience).

2.11. Apoptosis Assay. BALF cells from all groups were evaluated for apoptosis using an annexin V-FITC/propidium iodide (PI) apoptosis detection kit (BD Pharmingen), following the manufacturer's instructions. BALF cells were collected as mentioned previously, washed twice with PBS, centrifuged at $400 \times \mathrm{g}$ for $15 \mathrm{~min}$ and suspended in annexin $\mathrm{V}$ binding buffer, and incubated with annexin V-FITC in total darkness for $15 \mathrm{~min}$. PI was added to all samples immediately before data acquisition. A total of 10,000 events were acquired for each sample using the FACSCanto flow cytometer (Becton and Dickinson, San Jose, CA) [26]. A side-scatter gate was made to assess the apoptotic cells, and the results were evaluated by FACSDiva software and expressed as a percentage of late apoptotic cells (annexin ${ }^{+} / \mathrm{PI}^{+}$) from total gated cells.

2.12. Statistical Analysis. One-way ANOVA was used followed by Newman-Keuls multiple comparison test and Student's $t$-test to analyze differences between experimental groups. Survival differences were detected by the log-rank test. The results were considered significant when $p<0.05$. 
EPO treatment and $H$. capsulatum infection

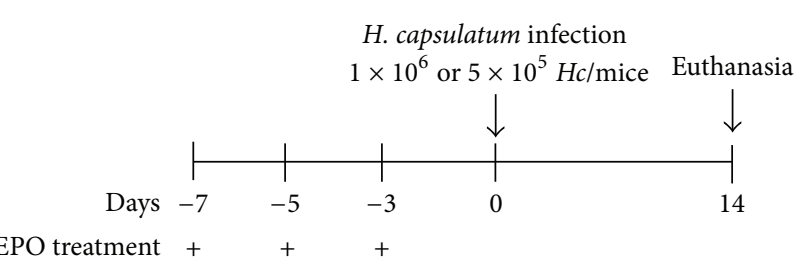

(a)

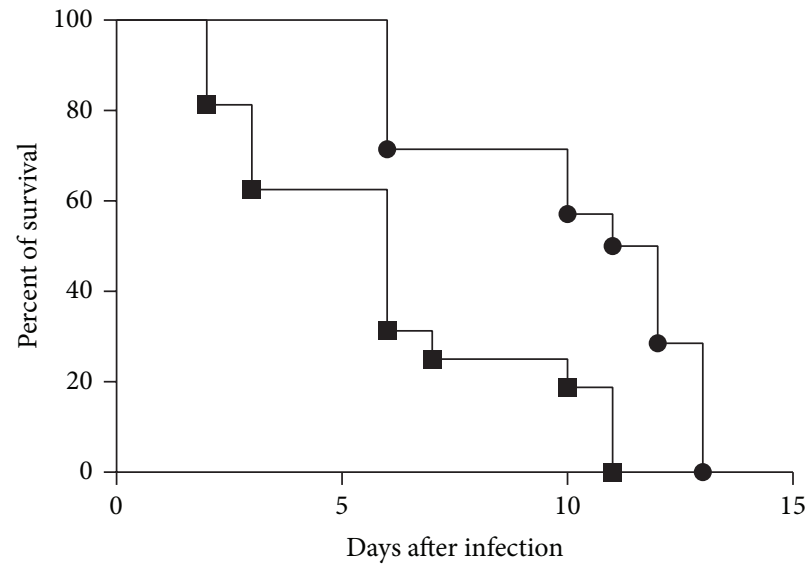

$\mathrm{Hc}$

$\mathrm{EPO}+\mathrm{Hc}$

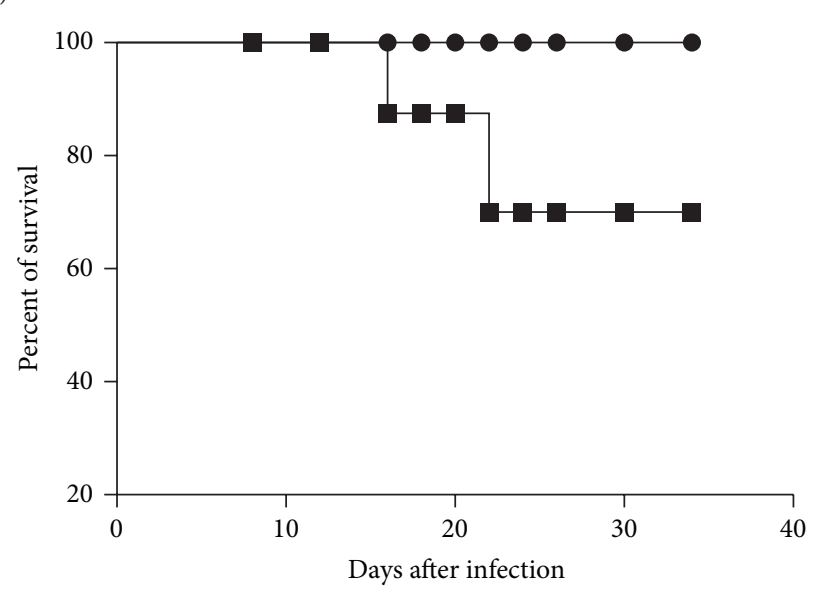

$H c$ $\mathrm{EPO}+\mathrm{Hc}$

(b)

(c)

FIGURE 1: EPO pretreatment decreases the survival of $\mathrm{Hc}$-infected mice. (a) Schematic representation of EPO treatment. In all experiments mice were treated with $45 \mathrm{U}$ EPO three times per week, one week before $H c$ infection with (b) lethal $\left(1 \times 10^{6}\right.$ yeasts/100 $\left.\mu \mathrm{L} / \mathrm{mouse}\right)$ or $(\mathrm{c})$ sublethal $\left(5 \times 10^{5}\right.$ yeasts $/ 100 \mu \mathrm{L} /$ mouse) (i.t.). Survival was followed up to 15 or 35 days, as indicated $(n=7)$. The log-rank test was used and differences were considered significant when $p<0.05$.

\section{Results}

3.1. EPO Increases Mortality of Hc-Infected Mice without Rising Fungal Burden. We observed that pretreatment with EPO (Figure 1(a)) increased the mortality of sublethal or lethal $\mathrm{Hc}$ infected mice (Figures 1(b) and 1(c)). The survival of non infected mice was not altered by EPO treatment following the same schedule (data not shown). Next, we investigate if increased mortality of infected EPO pretreated mice was due to augmentation of fungal burden in the lungs and spleen. For this experiment, 14-day postinfection fungal burden in lung and spleen was determined by counting CFU. As seen in Figure 2, EPO pretreatment did not alter the fungal burden in the organs, when compared to that observed in infected mice without EPO treatment. These results suggest that the increased mortality observed in EPO-treated mice was not due to increased fungal proliferation or dissemination.

3.2. EPO Decreases the Number but Increases Apoptosis of $B A L F$ Mononuclear Cells. The effect of EPO pretreatment on the cell populations in the bronchoalveolar space with or without infection was investigated. We observed a decrease in mononuclear cell counts (Figure 3(a)) without a change in neutrophil numbers (Figure $3(\mathrm{~b})$ ) in the BALF of EPO pretreated and $\mathrm{Hc}$-infected mice $(\mathrm{EPO}+\mathrm{Hc})$, when compared to infected EPO-untreated mice ( $H c$ group). Interestingly, EPO treatment of non infected animals resulted exclusively in significant increases in mononuclear cells in the bronchoalveolar space (Figure 3(a)). Since EPO pretreatment reduced the number of mononuclear cells in the BALF of infected mice, we investigated whether this was due to increased apoptosis of mononuclear cells. The results demonstrate a decrease in the number of late apoptotic cells $\left(\right.$ annexin $^{+} / \mathrm{PI}^{+}$) in BALF from the $H c$ group, when compared to control uninfected mice (Figure 3(b)). However, EPO pretreatment increased the number of late apoptotic cells present in BALF $(E P O+$ $H c$ group), in comparison to the $H c$ group. No differences were found in the number of early apoptotic or necrotic cells between EPO pretreated mice and untreated controls (data not shown).

3.3. EPO Increases Alveolar Macrophage Activation, Inflammation, and Lung Damage after Fungal Infection. To understand why EPO treatment increased the mortality of $\mathrm{Hc}$ infected mice without increasing fungal burden, we also investigated the degree of BALF macrophage activation and lung inflammation. Thus, the expression of the activation markers CD80, CD86, and MHC II was evaluated in $\mathrm{F} 4 / 80^{+}$ cells from BALF. F4/80 ${ }^{+}$is a pan marker of macrophage differentiation [27]. In $E P O+H c$ BALF higher numbers 


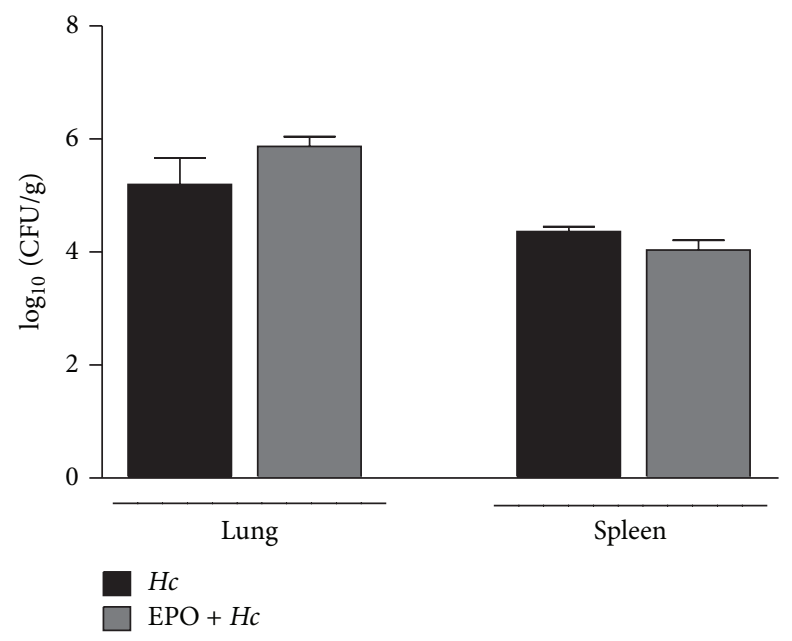

FIGURE 2: EPO pretreatment did not alter fungal burden in the lungs and spleen of $H c$-infected mice. $H c$ and $E P O+H c$ animals were infected i.t. with sublethal $\left(5 \times 10^{5}\right.$ yeasts/100 $\mu \mathrm{L} /$ mouse $)$ inoculum and fungal burden determined in lungs and spleen 14 days later. Fungal burden was expressed as $\log _{10}$ of the number of colony-forming units per gram of tissue (CFU/g). Mean \pm SEM values are from one representative of two independent experiments $(n=4-6)$. Non differences were determined using Newman-Keuls multiple comparison test.

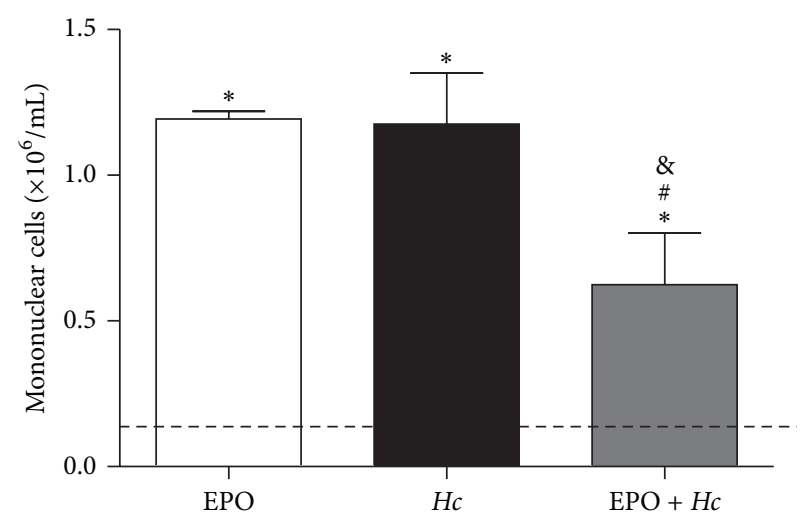

(a)

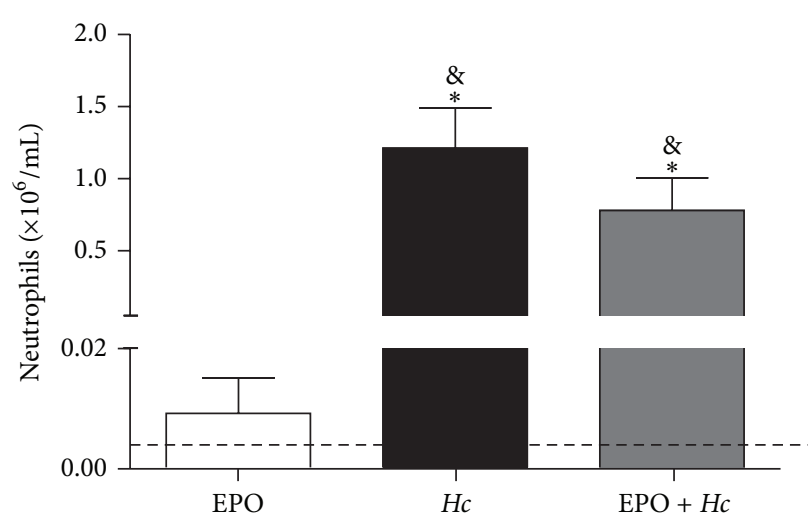

(b)

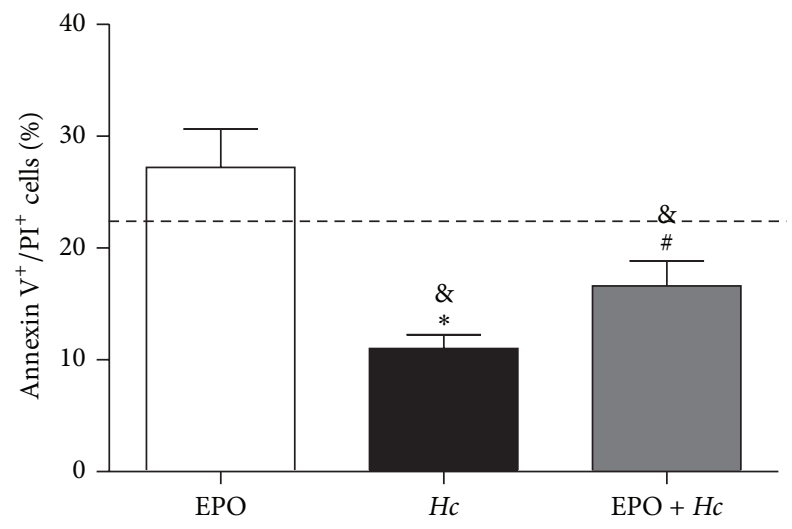

(c)

FIGURE 3: EPO pretreatment decreases the number of mononuclear cells and increases the number of cells in late apoptosis in BALF samples of $\mathrm{Hc}$-infected mice. 14 days after infection, BALF from uninfected mice treated with $45 \mathrm{U}$ of EPO (EPO) and from untreated (Hc) or EPO pretreated $(E P O+H c)$ mice infected with $H c\left(5 \times 10^{5}\right.$ yeasts $/ 100 \mu \mathrm{L} /$ mouse) were evaluated for numbers of (a) mononuclear cells and (b) neutrophils. (c) Flow cytometry using annexin/PI staining was used to detect late apoptotic cells (annexin $\left.{ }^{+} / \mathrm{PI}^{+}\right)$. ((a) and (b)) Values represent means \pm SEM and (c) means \pm SD of one representative of two independent experiments $(n=4-6)$. Newman-Keuls multiple comparison test was used and the differences were considered significant when $p<0.05 .{ }^{*}$ Versus $H c$; ${ }^{*}$ versus uninfected and EPO-untreated (dashed line); \& versus uninfected and EPO-treated mice. 


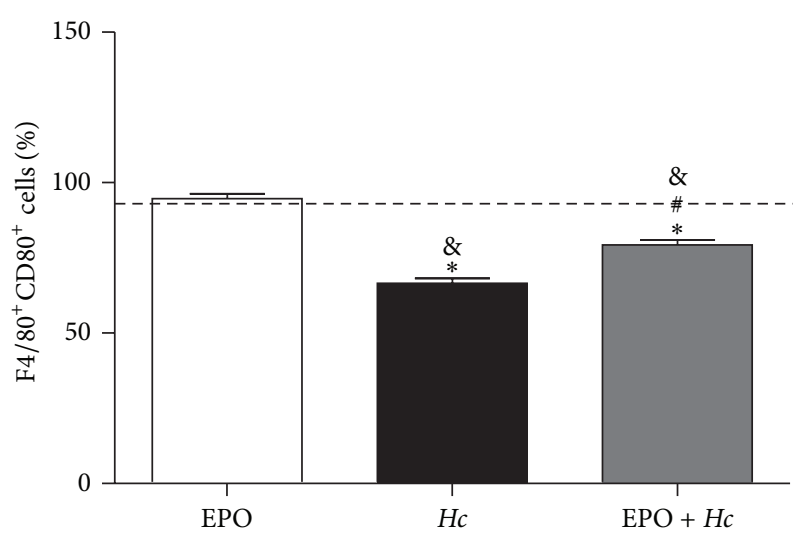

(a)

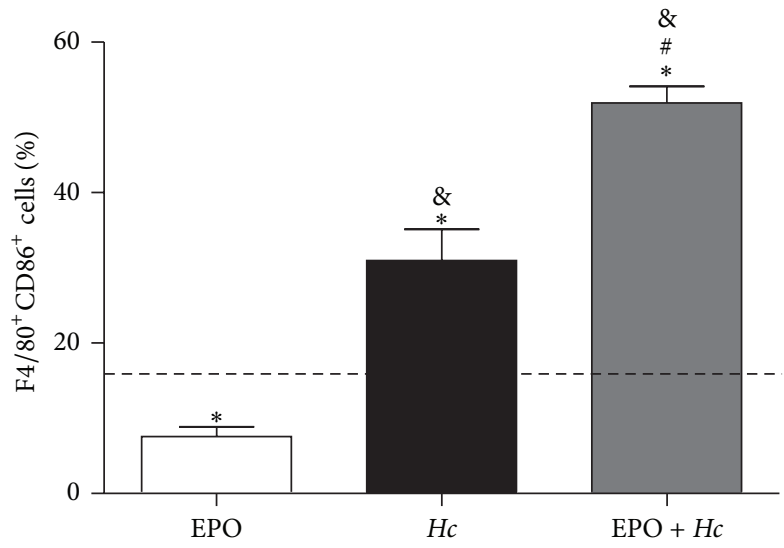

(b)

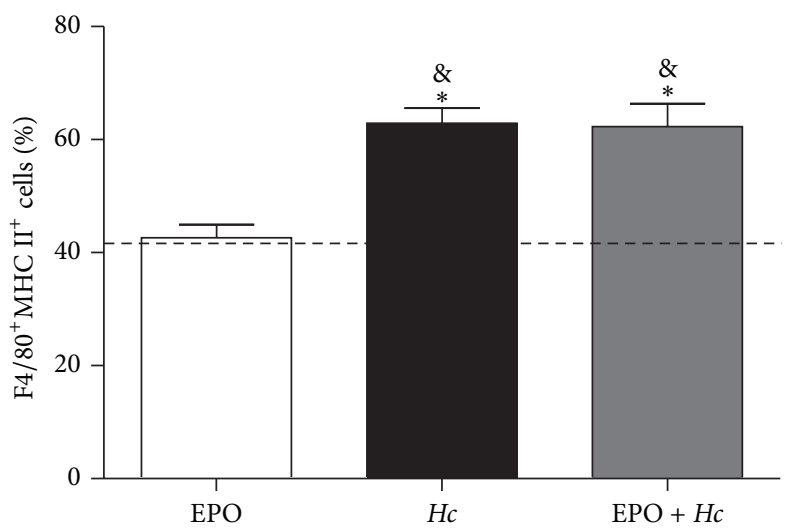

(c)

FIGURE 4: EPO pretreatment alters the expression of macrophage activation markers in $H c$-infected mice. 14 days after infection, BALF cell populations from uninfected mice EPO-treated (EPO) and from untreated $(H c)$ or EPO pretreated $(E P O+H c)$ mice infected with $H c(5$ $\times 10^{5}$ yeasts $/ 100 \mu \mathrm{L} /$ mouse) were analyzed by flow cytometry for the percentage of $\mathrm{F} 4 / 80^{+} \mathrm{CD} 80^{+}$(a), F4/80 ${ }^{+} \mathrm{CD} 86^{+}$(b), and F4/80 ${ }^{+} \mathrm{MHC}$ $\mathrm{II}^{+}$(c) cells. Means \pm SEM values from one representative of two independent experiments are shown $(n=4-6)$. Newman-Keuls multiple comparison test was used and the differences were considered significant when $p<0.05 .{ }^{*}$ Versus $H c$; ${ }^{*}$ versus uninfected and EPO-untreated (dashed line); ${ }^{\&}$ versus uninfected and EPO-treated mice.

of F4/80 ${ }^{+}$cells expressing CD80 and CD86 molecules were found (Figures 4(a) and 4(b)), while the proportion of F4/80 cells expressing MHC II was not affected (Figure 4(c)), in comparison to only EPO-treated mice. However, the expression of CD80 molecules was decreased in $E P O+H c$ and $H c$ animals, when compared to uninfected control and to EPO-treated animals (Figure 4(a)).

$H c$ infection increased IFN- $\gamma$, IL-6, MIP- $1 \alpha$, and MCP-1 production in lungs relative to those observed in uninfected and untreated mice. EPO pretreatment further increased cytokine and chemokine concentrations in infected mice (Figure 5). Hc infection increased TNF- $\alpha$, KC (IL-8), and RANTES, but no further alterations were observed in the $E P O+H c$ group (data not shown). Because lipid mediators might contribute to lung inflammation, we evaluated $\mathrm{LTB}_{4}$ and $\mathrm{PGE}_{2}$ production in the lungs of infected mice with or without EPO pretreatment. In the $E P O+H c$ group, we observed decreased $\mathrm{PGE}_{2}$ (Figure 6(a)) but increased $\mathrm{LTB}_{4}$ (Figure 6(b)) concentrations compared to that found in the $\mathrm{Hc}$ group. Infected mice treated or not with EPO showed higher amounts of eicosanoids than uninfected animals, EPO-treated or not (Figure 6).

As we observed increased inflammatory mediator concentrations, we assessed lung inflammation and parenchymal damage by histopathological analysis. Corroborating our previous data [5], we observed that $H c$ infection induced lung inflammation with severely compromised lung architecture (Figures 7(c) and 7(d)). EPO pretreatment of infected mice clearly increased lung inflammation and damage, as seen by the expansion of LLAs (Figures 7(d) and 7(e)). We observed that EPO pretreatment increased inflammatory cellular infiltration, mainly with mononuclear cells, and decreased alveolar structures in the lung parenchyma, suggesting that the impairment of respiratory capacity may be responsible for death of the mice.

Taken together, our results suggest that pretreatment with EPO decreases the survival of infected mice due to excessive lung inflammation, which severely compromises lung architecture, impairing normal respiratory capacity. Excessive inflammation in EPO pretreated mice appears to be due 


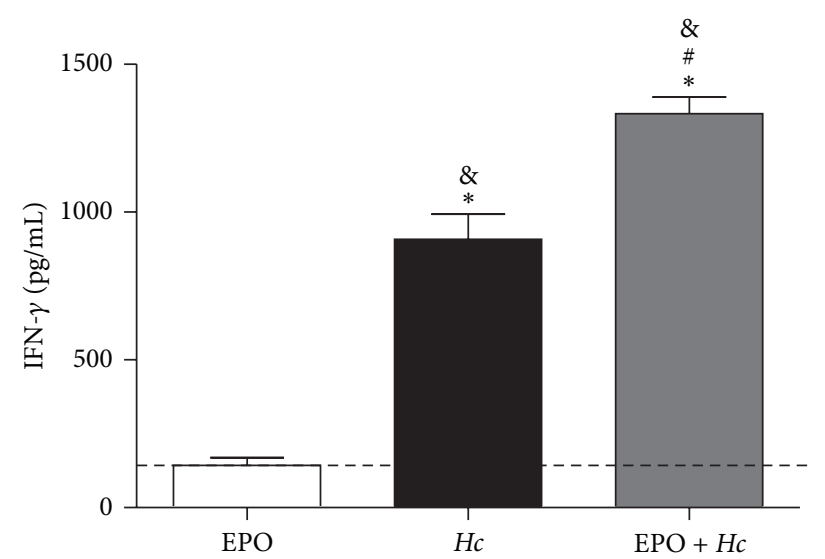

(a)

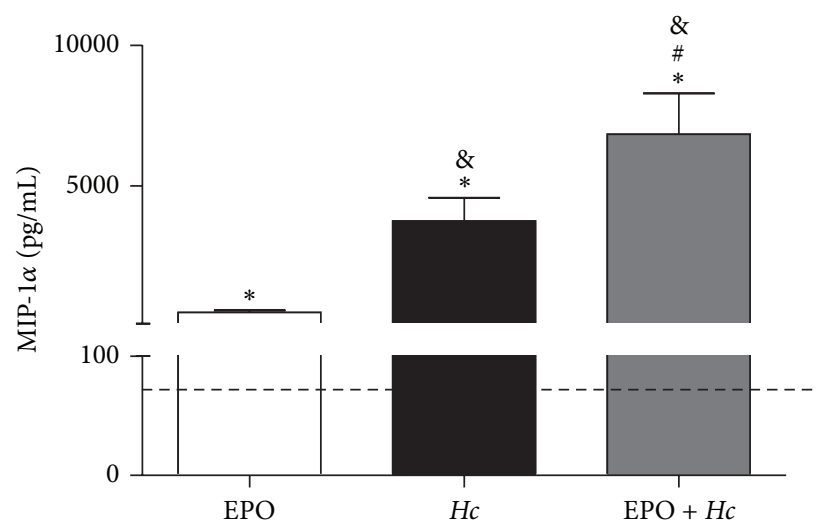

(c)

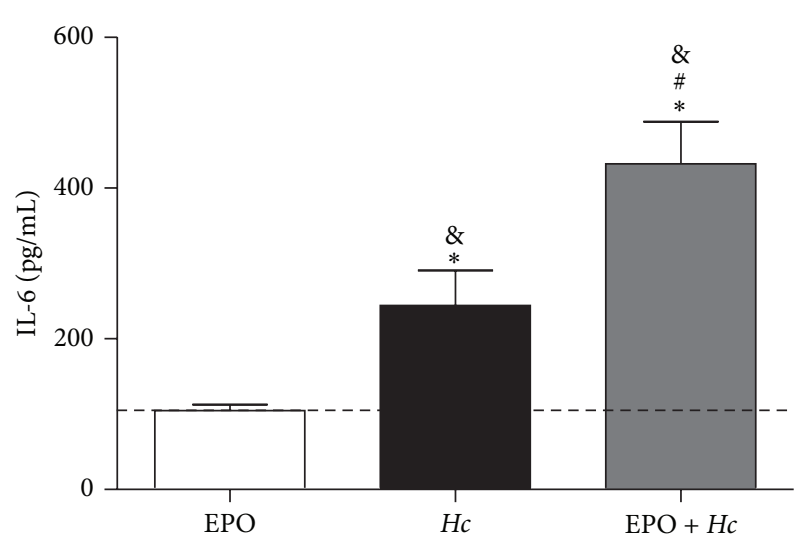

(b)

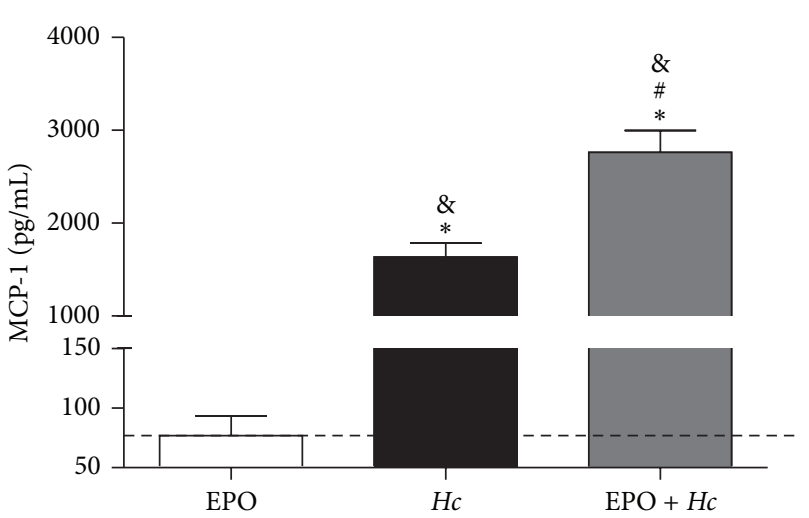

(d)

FIGURE 5: EPO pretreatment increases proinflammatory cytokines and chemokines in lungs from $H c$-infected mice. Lungs were removed from uninfected mice treated with $45 \mathrm{U}$ EPO $(\mathrm{EPO})$ or from untreated $(H c)$ or EPO pretreated $(E P O+H c)$ mice infected with $H c(5 \times$ $10^{5}$ yeasts $/ 100 \mu \mathrm{L} /$ mouse). Lungs were removed 14 days after infection and homogenized, and the concentrations of IFN- $\gamma$ (a), IL-6 (b), MIP$1 \alpha$ (c), and MCP-1 (d) were assessed in the supernatants using ELISA. Means \pm SEM values from one representative experiment of two independent experiments are shown $(n=4-6)$. Newman-Keuls multiple comparison test was used and the differences were considered significant when $p<0.05 .{ }^{\#}$ Versus $\mathrm{Hc}$; ${ }^{*}$ versus uninfected and EPO-untreated (dashed line); ${ }^{\text {\& }}$ versus uninfected and EPO-treated mice.

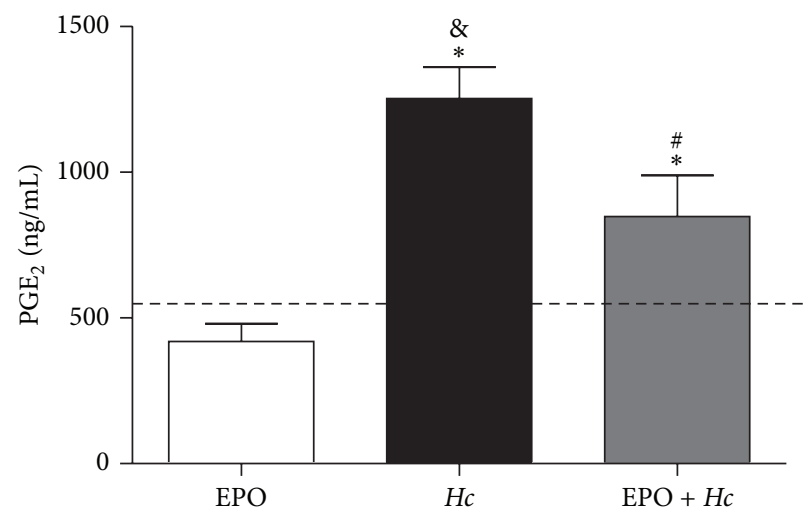

(a)

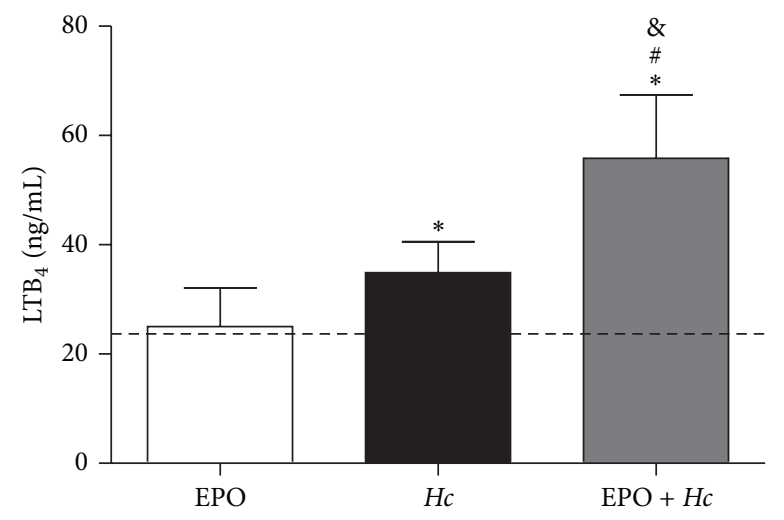

(b)

FIGURE 6: EPO pretreatment alters $\mathrm{PGE}_{2}$ and $\mathrm{LTB}_{4}$ production in lungs from $\mathrm{Hc}$-infected mice. Lungs were removed from uninfected mice treated with $45 \mathrm{U}$ EPO $(\mathrm{EPO})$ or from untreated $(H c)$ or EPO pretreated $(E P O+H c)$ mice infected with $H c\left(5 \times 10^{5}\right.$ yeasts/100 $\left.\mu \mathrm{L} / \mathrm{mouse}\right)$. Lungs were removed 14 days after infection and homogenized, and eicosanoids were purified as described in the Materials and Methods. PGE 2 (a) and $\mathrm{LTB}_{4}$ (b) concentration was quantified in the purified homogenates by HPLC-MS/MS. Means \pm SEM values from one representative experiment are shown $(n=4-6)$. Newman-Keuls multiple comparison test was used and the differences were considered significant when $p<0.05$. " Versus $\mathrm{Hc}$; ${ }^{*}$ versus uninfected and EPO-untreated (dashed line); ${ }^{*}$ versus uninfected and EPO-treated mice. 


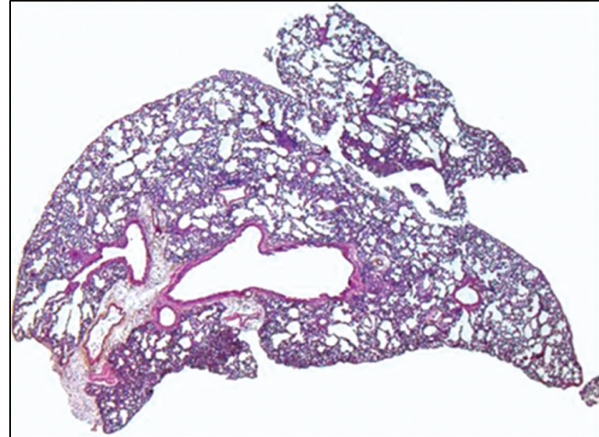

(a)

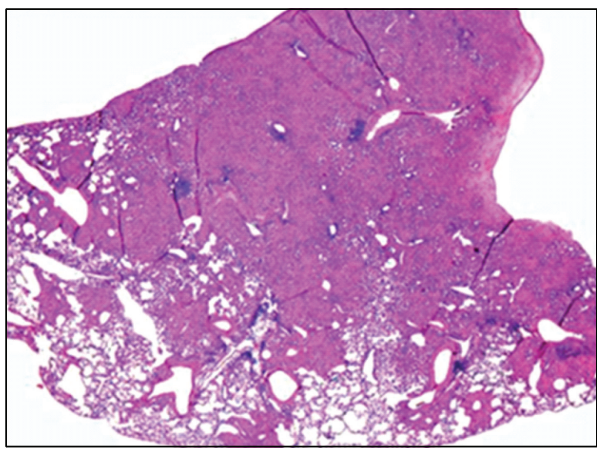

(c)

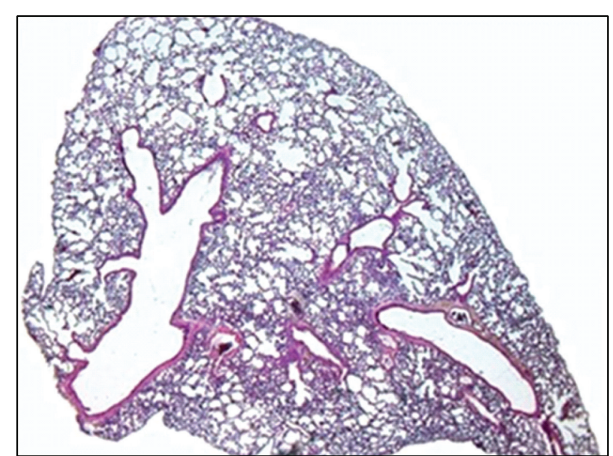

(b)

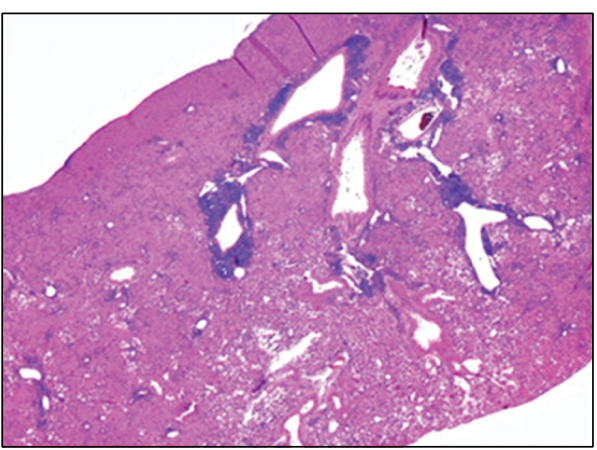

(d)

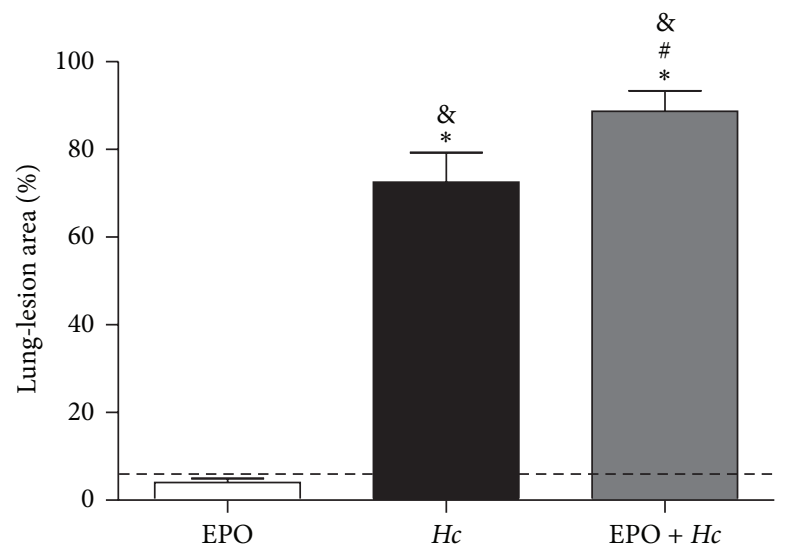

(e)

FIGURE 7: EPO pretreatment increases the area of lung tissue damage in $H c$-infected mice. Lungs removed from uninfected and untreated mice (CTL) (a), EPO pretreated and uninfected mice (EPO) (b), $H c$-infected only $(H c)(c)$, and EPO pretreated mice infected $(5 \times$ $10^{5}$ yeasts $/ 100 \mu \mathrm{L} /$ mouse $)(E P O+H c)(\mathrm{d})$. Lungs were removed 14 days after infection, processed, and stained using H\&E for routine histological examination. (e) Lung-lesion area was calculated by measuring three lungs per group and was expressed as total lung area using Adobe Photoshop. Mean \pm SEM values from one independent experiment are shown. Representative photomicrography of lung of one animal per group from $n=4-6$. Newman-Keuls multiple comparison test was used and the differences were considered significant when $p<0.05$. ${ }^{\#}$ Versus Hc; ${ }^{*}$ versus CTL (dashed line); ${ }^{*}$ versus EPO.

to increased activation of macrophages that release higher amounts of inflammatory mediators than macrophages from infected mice in the absence of EPO pretreatment.

\section{Discussion}

Nonerythroid effects of EPO have been described in several studies $[11,13,14,18]$. Among their nonclassical effects, EPO is known as a macrophage activating factor [11] and seems to be involved in lipid mediator production [20]. Because of the importance of macrophages and lipid mediators for the control of fungal infection, the purpose of this study was to investigate the effect of EPO pretreatment in the progression of lung infection induced by $\mathrm{Hc}$. We observed that EPO treatment for one week before $\mathrm{Hc}$ infection increased mice mortality without corresponding increases in fungal burden 
in the lungs or spleen, suggesting no correlation with fungal proliferation and/or dissemination. Our analysis of different aspects of the innate immune response elicited by $\mathrm{Hc}$ infection in EPO pretreated mice revealed that increased mortality may result from excessive lung inflammation due to increased macrophage activation and the production of inflammatory mediators.

Our data are in agreement with the report of Nairz et al. [19] showing that $5 \mathrm{U} / \mathrm{g}$ EPO augmented the mortality of mice infected with $S$. typhimurium as compared to infected mice in the absence of EPO. Increased mortality was accompanied with reduced NO production and cytokines involved in controlling host resistance. The production of NO is also important for the control of $\mathrm{Hc}$ infection [3, 28]. However, pretreatment with EPO did not significantly alter NO production (data not shown), and fungal burden was not increased. However, mononuclear cell numbers in the bronchoalveolar space were decreased in $E P O+H c$, as compared to the $H c$ group. These results are surprising because mononuclear cells are the most efficient at triggering fungal death during $\mathrm{Hc}$ infection [3]. We also found a reduced number of apoptotic cells recovered from the BALF of $\mathrm{Hc}$-infected mice. The pretreatment with EPO partially increased apoptosis, which might explain the reduction in mononuclear cell numbers found in BALF samples of EPO pretreated and infected mice, compared to infected mice not pretreated with EPO.

The fact that the reduction in mononuclear cell numbers in EPO pretreated mice did not result in increased fungal burden might be explained by the higher activation of alveolar macrophages observed in these mice. Pretreatment with $\mathrm{EPO}$ before $\mathrm{Hc}$ infection increased the frequency of $\mathrm{CD} 80^{+}$and $\mathrm{CD} 86^{+}$(but not $\mathrm{MHC} \mathrm{II}^{+}$cells) in the $\mathrm{F} 4 / 80^{+}$ macrophage population from BALF samples. Similarly, Lifshitz and colleagues [11] reported that the spleens of both C57BL/6 mice treated with $\mathrm{rHuEPO}$ and $\operatorname{tg} 6$ mice (which produce EPO excessively) had increased numbers of $\mathrm{F} 4 / 80^{+}$ cells coexpressing CD80 and MHC II molecules. In a previous study using the same mouse model, these authors also showed increased frequency and expression of CD80 in CD11c cells [29]. Moreover, the pretreatment with EPO also augmented the production of inflammatory mediators such as IL-6, IFN- $\gamma, \mathrm{MCP}-1, \mathrm{MIP}-1 \alpha$, and $\mathrm{LTB}_{4}$ in $\mathrm{Hc}$ mice. Although these mediators are important for the control of infection $[5,30-33]$, their excessive production might be detrimental to the host by triggering excessive lung inflammation. Disproportionate lung inflammation was confirmed by histopathological analysis in the $E P O+H c$ group (Figure 7), which demonstrated increases in LLA. Our data are not in agreement with a previous study showing that EPO pretreatment reduced IL- 6 , TNF- $\alpha$, and IL- $1 \beta$ production in the liver during S. typhimurium infection [19].

In addition to cytokines, the eicosanoids LT and PG also play a central role in controlling $H c$ infection [5-8]. Previous data from our laboratory demonstrated that PGs impair host control of $\mathrm{Hc}$ infection and that PG synthesis inhibition by celecoxib led to yeast elimination and infection control [8]. In the present study, we found increased $\mathrm{PGE}_{2}$ concentration in $\mathrm{Hc}$-infected mice, but EPO treatment before the infection reduced $\mathrm{PGE}_{2}$ concentration, although no reduction in mortality was associated with this phenomenon. It is known that $\mathrm{PGE}_{2}$ plays a role in apoptotic events. While $\mathrm{PGE}_{2}$ induces apoptosis in some cell types, including resting immature and mature human lymphocytes [34] and epithelial cells [35], inhibition of apoptosis by $\mathrm{PGE}_{2}$ has been reported for other cell types, including neutrophils [36-38]. Similarly, in the present report, there was a negative association between $\mathrm{PGE}_{2}$ concentration and the number of apoptotic cells in BALF samples.

Overall, our data strongly suggest that excessive inflammation caused by exacerbated activation of alveolar macrophages increases lung inflammation, tissue damage, and mortality in EPO pretreated and infected mice. These results are consistent with a recent report from Doitsh and colleagues [39] demonstrating the role of excessive inflammation in maintaining $\mathrm{CD}^{+} \mathrm{T}$ cell death during HIV infection. This phenomenon was related to cell death of nonpermissive $\mathrm{CD} 4^{+} \mathrm{T}$ cells by pyroptosis, which is caused by excessive inflammation and also promotes further inflammation, maintaining the cycle of cell death and compromising the patient's quality of life.

In humans, the use of recombinant EPO is very common in patients with chronic renal disease and/or those undergoing hemodialysis, because various forms of anemia are common in these cases [40]. Anemia, which impairs quality of life, occurs primarily due to deficiency in the production of EPO by the kidney but can be exacerbated by iron deficiency, which contributes to the shortened lifespan of erythrocytes, among other complications. However, treatment is not based solely on EPO administration; antiproliferative cytokines and stimulation of iron uptake are used in combination with EPO in attempts to reverse the anemia [41].

It is important to highlight that although EPO treatment is crucial for control of anemia in patients with chronic renal disease or those undergoing hemodialysis, our study focused on inappropriate immune responses that these patients might generate prior to a potential fungal infection acquired during the treatment period, which could contribute to their morbidity.

\section{Conflict of Interests}

The authors report no potential conflict of interests.

\section{Authors' Contribution}

Gisele Aparecida Locachevic was the principal investigator, wrote the paper, and takes primary responsibility for the paper. Adriana Secatto, Priscilla Aparecida Tartari Pereira, Caroline Fontanari, Alyne Fávero Galvão, and Morgana Kelly Borges Prado assisted with laboratory procedures. Karina Furlani Zoccal and Tânia Petta performed the quantification of lipid mediators, and Luiz Alberto Beraldo Moraes helped in the use of mass spectrometry and HPLC. Simone Gusmão Ramos helped with the histological analysis. Adriana Secatto and Carlos Artério Sorgi assisted in the discussions of the results. Fabíola Attie de Castro helped with scientific discussion and reviewed the paper. Lúcia Helena Faccioli 
acted as scientific advisor, designed the study, obtained the funding grants, and wrote, discussed, and reviewed the paper.

\section{Acknowledgments}

This work was supported by the Sao Paulo Research Foundation (FAPESP, Grants no. 2011/04704-7 and no. 2009/071695) and National Council for Scientific and Technological Development (CNPq). The funders had no role in the study design, data collection and analysis, decision to publish, or preparation of the paper. The authors would like to thank Dr. Bernhard Ryffel for scientific support and Fabiana R. Morais and Elaine M. Floriano for technical assistance.

\section{References}

[1] G. S. Deepe Jr., "Immune response to early and late Histoplasma capsulatum infections," Current Opinion in Microbiology, vol. 3, no. 4, pp. 359-362, 2000.

[2] L. C. Severo, S. M. Oliveira, F. Irion, N. S. Porto, and T. L. Londero, "Histoplasmosis in Rio Grande do Sul, Brazil: a 21-year experience," Revista do Instituto de Medicina Tropical de São Paulo, vol. 43, no. 4, pp. 183-187, 2001.

[3] S. L. Newman, "Macrophages in host defense against Histoplasma capsulatum," Trends in Microbiology, vol. 7, no. 2, pp. 6771, 1999.

[4] J. Z. Haeggström and C. D. Funk, "Lipoxygenase and leukotriene pathways: biochemistry, biology, and roles in disease," Chemical Reviews, vol. 111, no. 10, pp. 5866-5896, 2011.

[5] A. I. Medeiros, A. Sá-Nunes, E. G. Soares, C. M. Peres, C. L. Silva, and L. H. Faccioli, "Blockade of endogenous leukotrienes exacerbates pulmonary histoplasmosis," Infection and Immunity, vol. 72, no. 3, pp. 1637-1644, 2004.

[6] A. I. Medeiros, A. Sá-Nunes, W. M. Turato et al., "Leukotrienes are potent adjuvant during fungal infection: effects on memory T cells," The Journal of Immunology, vol. 181, no. 12, pp. 85448551, 2008.

[7] A. Secatto, L. C. Rodrigues, C. H. Serezani et al., "5-lipoxygenase deficiency impairs innate and adaptive immune responses during fungal infection," PLoS ONE, vol. 7, no. 3, Article ID e31701, 2012.

[8] P. A. T. Pereira, B. C. Trindade, A. Secatto et al., "Celecoxib improves host defense through prostaglandin inhibition during histoplasma capsulatum infection," Mediators of Inflammation, vol. 2013, Article ID 950981, 11 pages, 2013.

[9] H. Harizi, J.-B. Corcuff, and N. Gualde, "Arachidonic-acidderived eicosanoids: roles in biology and immunopathology," Trends in Molecular Medicine, vol. 14, no. 10, pp. 461-469, 2008.

[10] J. L. Stow, P. C. Low, C. Offenhäuser, and D. Sangermani, "Cytokine secretion in macrophages and other cells: pathways and mediators," Immunobiology, vol. 214, no. 7, pp. 601-612, 2009.

[11] L. Lifshitz, G. Tabak, M. Gassmann, M. Mittelman, and D. Neumann, "Macrophages as novel target cells for erythropoietin," Haematologica, vol. 95, no. 11, pp. 1823-1831, 2010.

[12] A. P. Maxwell, T. R. J. Lappin, C. F. Johnston, J. M. Bridges, and M. G. McGeown, "Erythropoietin production in kidney tubular cells," British Journal of Haematology, vol. 74, no. 4, pp. 535-539, 1990.
[13] M. Lombardero, K. Kovacs, and B. W. Scheithauer, "Erythropoietin: a hormone with multiple functions," Pathobiology, vol. 78, no. 1, pp. 41-56, 2011.

[14] M. L. Brines, P. Ghezzi, S. Keenan et al., "Erythropoietin crosses the blood-brain barrier to protect against experimental brain injury," Proceedings of the National Academy of Sciences of the United States of America, vol. 97, no. 19, pp. 10526-10531, 2000.

[15] A.-L. Sirén, M. Fratelli, M. Brines et al., "Erythropoietin prevents neuronal apoptosis after cerebral ischemia and metabolic stress," Proceedings of the National Academy of Sciences of the United States of America, vol. 98, no. 7, pp. 4044-4049, 2001.

[16] K. Nishimura, H. Nakaya, H. Nakagawa, S. Matsuo, Y. Ohnishi, and S. Yamasaki, "Effect of Trypanosoma brucei brucei on erythropoiesis in infected rats," Journal of Parasitology, vol. 97, no. 1, pp. 88-93, 2011.

[17] M. Nairz, T. Sonnweber, A. Schroll, I. Theurl, and G. Weiss, "The pleiotropic effects of erythropoietin in infection and inflammation," Microbes and Infection, vol. 14, no. 3, pp. 238246, 2012.

[18] K. Kaiser, A. Texier, J. Ferrandiz et al., "Recombinant human erythropoietin prevents the death of mice during cerebral malaria," The Journal of Infectious Diseases, vol. 193, no. 7, pp. 987-995, 2006.

[19] M. Nairz, A. Schroll, A. R. Moschen et al., "Erythropoietin contrastingly affects bacterial infection and experimental colitis by inhibiting nuclear factor-kappaB-inducible immune pathways," Immunity, vol. 34, no. 1, pp. 61-74, 2011.

[20] M. Mason-Garcia, S. Clejan, J.-S. Tou, and B. S. Beckman, "Signal transduction by the erythropoietin receptor: Evidence for the activation of phospholipases A2 and C," The American Journal of Physiology -Cell Physiology, vol. 262, no. 5, pp. C1197C1203, 1992.

[21] M. Hagiwara, D. B. McNamara, I. L. Chen, and J. W. Fisher, "Role of endogenous prostaglandin E2 in erythropoietin production and dome formation by human renal carcinoma cells in culture," Journal of Clinical Investigation, vol. 74, no. 4, pp. 1252-1261, 1984.

[22] A. Kurtz, W. Jelkmann, J. Pfeilschifter, and C. Bauer, "Role of prostaglandins in hypoxia-stimulated erythropoietin production," The American Journal of Physiology, vol. 249, no. 1, part 1, pp. C3-C8, 1985.

[23] A.-K. Boer, A. L. Drayer, H. Rui, and E. Vellenga, "Prostaglandin-E2 enhances EPO-mediated STAT5 transcriptional activity by serine phosphorylation of CREB," Blood, vol. 100, no. 2, pp. 467-473, 2002.

[24] V. L. G. Galich, A. Purchio, and C. R. Paula, "A new fluorescent viability test for fungi cells," Mycopathologia, vol. 66, no. 3, pp. 175-177, 1979.

[25] A. Sá-Nunes, A. I. Medeiros, R. Nicolete et al., "Efficacy of cell-free antigens in evaluating cell immunity and inducing protection in a murine model of histoplasmosis," Microbes and Infection, vol. 7, no. 4, pp. 584-592, 2005.

[26] Z. Xu, X. Chen, S. Fu et al., "Dehydrocorydaline inhibits breast cancer cells proliferation by inducing apoptosis in MCF-7 cells," The American Journal of Chinese Medicine, vol. 40, no. 1, pp. 177$185,2012$.

[27] D. A. Hume, "The mononuclear phagocyte system," Current Opinion in Immunology, vol. 18, no. 1, pp. 49-53, 2006.

[28] T. E. Lane, G. C. Otero, B. A. Wu-Hsieh, and D. H. Howard, "Expression of inducible nitric oxide synthase by stimulated macrophages correlates with their antihistoplasma activity," Infection and Immunity, vol. 62, no. 4, pp. 1478-1479, 1994. 
[29] L. Lifshitz, S. Prutchi-Sagiv, M. Avneon, M. Gassmann, M. Mittelman, and D. Neumann, "Non-erythroid activities of erythropoietin: functional effects on murine dendritic cells," Molecular Immunology, vol. 46, no. 4, pp. 713-721, 2009.

[30] D. N. Kroetz and G. S. Deepe, "The role of cytokines and chemokines in Histoplasma capsulatum infection," Cytokine, vol. 58, no. 1, pp. 112-117, 2012.

[31] A. I. Medeiros, V. L. D. Bonato, A. Malheiro, A. R. V. Dias, C. L. Silva, and L. H. Faccioli, "Histoplasma capsulatum inhibits apoptosis and Mac-1 expression in leucocytes," Scandinavian Journal of Immunology, vol. 56, no. 4, pp. 392-398, 2002.

[32] A. I. Medeiros, A. Malheiro, P. J. Jose, D. M. Conroy, T. J. Williams, and L. H. Faccioli, "Differential release of MIP-1 $\alpha$ and eotaxin during infection of mice by Histoplasma capsulatum or inoculation of $\beta$-glucan," Inflammation Research, vol. 53 , no. 8, pp. 351-354, 2004.

[33] P. Zhou, M. C. Sieve, J. Bennett et al., "IL-12 prevents mortality in mice infected with Histoplasma capsulatum through induction of IFN- $\gamma$," The Journal of Immunology, vol. 155, no. 2, pp. 785-795, 1995.

[34] F. Pica, O. Franzese, C. D’Onofrio, E. Bonmassar, C. Favalli, and E. Garaci, "Prostaglandin E2 induces apoptosis in resting immature and mature human lymphocytes: A c-Mycdependent and Bcl-2-independent associated pathway," Journal of Pharmacology and Experimental Therapeutics, vol. 277, no. 3, pp. 1793-1800, 1996.

[35] H. N. Jabbour, R. W. Kelly, and S. C. Boddy, "Autocrine/ paracrine regulation of apoptosis in epithelial cells by prostaglandin E2," Prostaglandins Leukotrienes \& Essential Fatty Acids, vol. 67, no. 5, pp. 357-363, 2002.

[36] V. Leone, A. Di Palma, P. Ricchi et al., "PGE2 inhibits apoptosis in human adenocarcinoma Caco-2 cell line through Ras-PI3K association and cAMP-dependent kinase A activation," American Journal of Physiology: Gastrointestinal and Liver Physiology, vol. 293, no. 4, pp. G673-G681, 2007.

[37] T. Hoshino, S. Tsutsumi, W. Tomisato, H.-J. Hwang, T. Tsuchiya, and T. Mizushima, "Prostaglandin $\mathrm{E}_{2}$ protects gastric mucosal cells from apoptosis via $\mathrm{EP}_{2}$ and $\mathrm{EP}_{4}$ receptor activation," Journal of Biological Chemistry, vol. 278, no. 15, pp. 12752-12758, 2003.

[38] L. Ottonello, R. Gonella, P. Dapino, C. Sacchetti, and F. Dallegri, "Prostaglandin E2 inhibits apoptosis in human neutrophilic polymorphonuclear leukocytes: role of intracellular cyclic AMP levels," Experimental Hematology, vol. 26, no. 9, pp. 895-902, 1998.

[39] G. Doitsh, N. L. K. Galloway, X. Geng et al., "Cell death by pyroptosis drives CD4 T-cell depletion in HIV-1 infection," Nature, vol. 505, no. 7484, pp. 509-514, 2014.

[40] M. A. Atkinson and S. L. Furth, "Anemia in children with chronic kidney disease," Nature Reviews Nephrology, vol. 7, no. 11, pp. 635-641, 2011.

[41] G. Weiss and L. T. Goodnough, "Anemia of chronic disease," The New England Journal of Medicine, vol. 352, no. 10, pp. 1011-1023, 2005. 


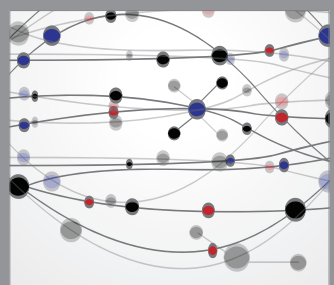

The Scientific World Journal
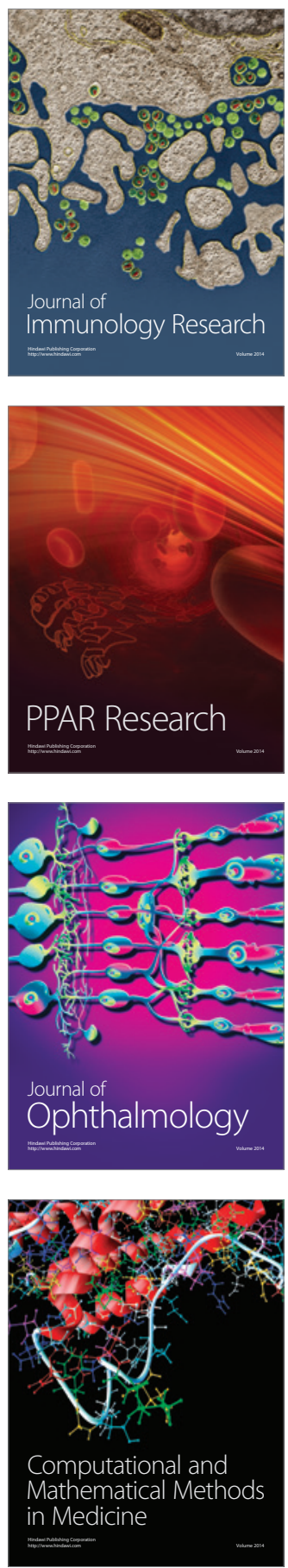

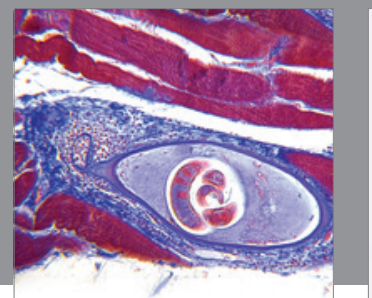

Gastroenterology

Research and Practice
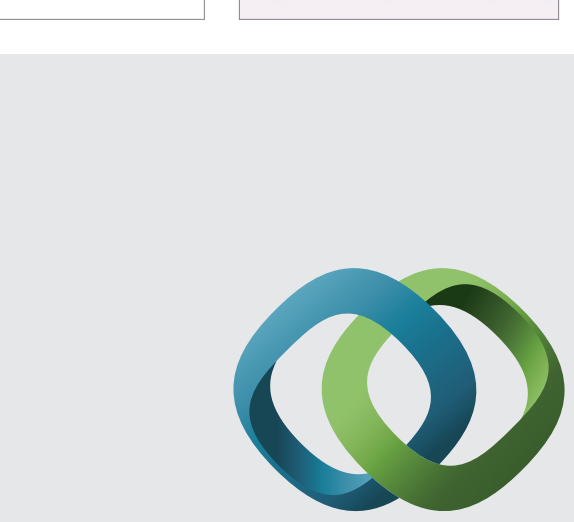

\section{Hindawi}

Submit your manuscripts at

http://www.hindawi.com
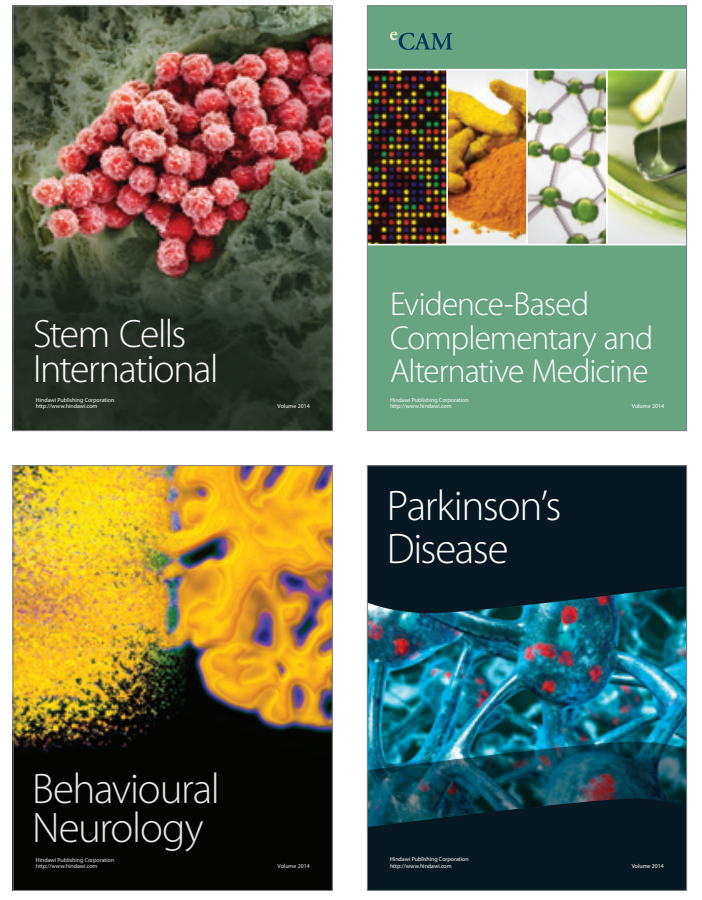
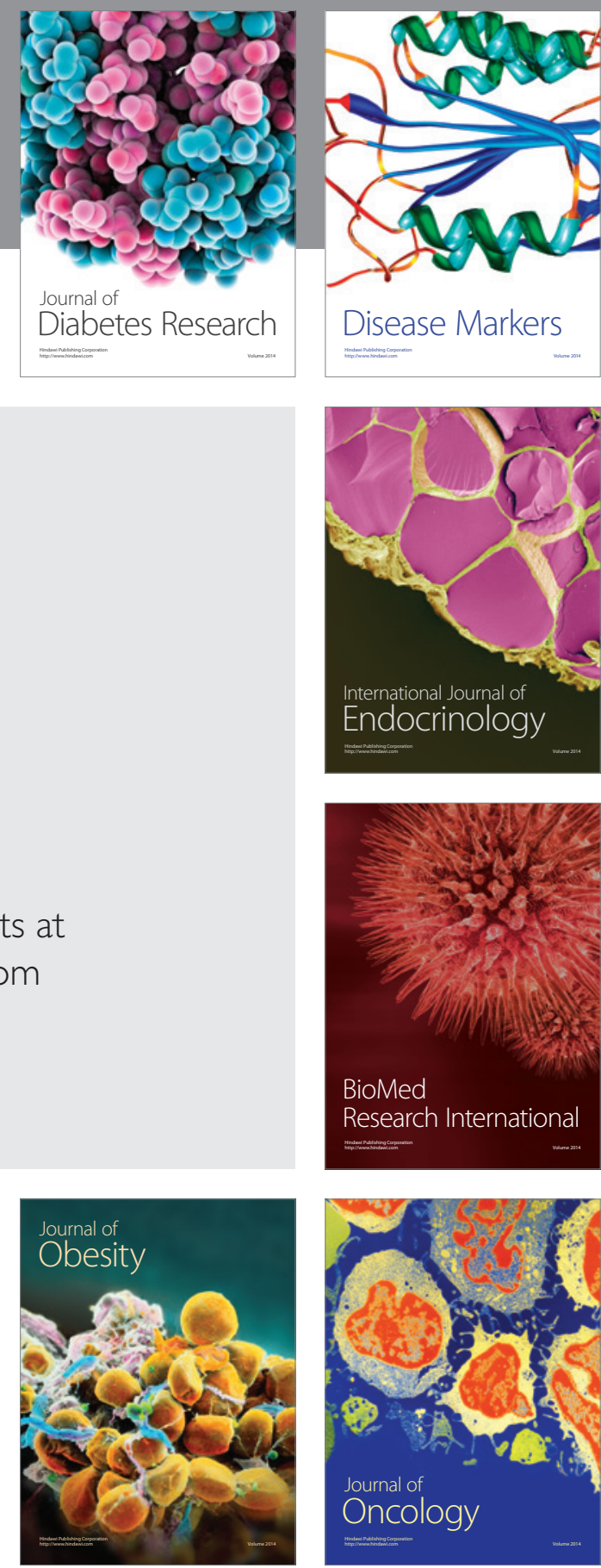

Disease Markers
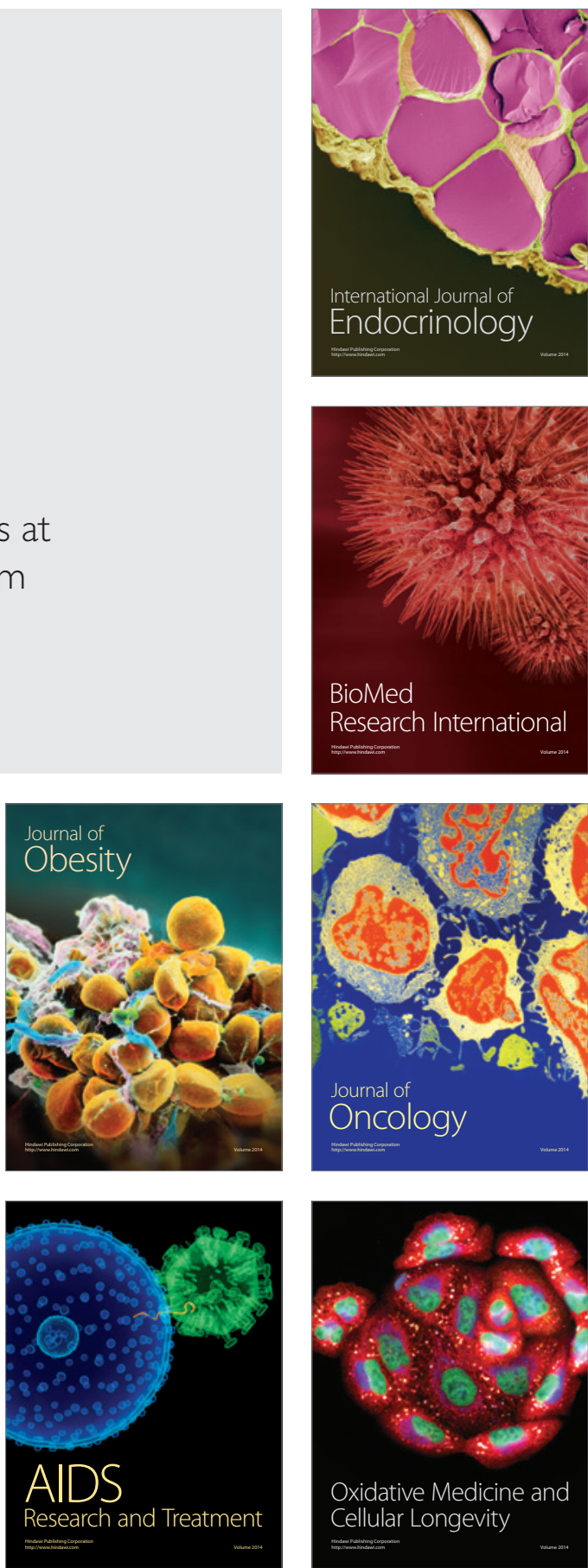